\title{
Towards Inclusive and Sustainable Industrial Development
}

YONG LI

\begin{abstract}
When formulating the 2030 Agenda for Sustainable Development, the international community realized a new development paradigm was needed to address global poverty. Expanding upon the previous level of engagement, the resulting universal, transformative and integrated agenda applies new approaches to accelerate progress, reflects the interconnectedness of today's economies, industries, societies and natural environment and recognizes the importance of inclusive and sustainable industrial development for poverty eradication.
\end{abstract}

KEYWORDS economic growth; inclusive and sustainable industry; manufacturing, environment; partnership; resilience

\section{Rethinking in the context of the 2030 Agenda for Sustainable Development}

The process leading to the new development agenda for the years beyond 2015 provided an extraordinary opportunity for the international community to reflect on the successes and failures of 'business as usual' and renew the global partnership for development and cooperation. The results of 'aid' efforts have to date been mixed. While concrete steps have been taken in certain areas, and the recent growth rates of some developing countries have been impressive, an intolerable level of poverty still exists, and an increasing number of people remain in need of basic goods and services. A growing population, increased pressure on natural resources and the inexorable evidence of anthropogenic climate change exacerbate poverty and vulnerability.

When formulating the 2030 Agenda for Sustainable Development, United Nations Member States and agencies realized that addressing development with an 'aid' agenda alone would not be enough. The new development pathway would not only need to build on the experience of the Millennium Development Goals (MDGs), but also need to go far beyond the previous level of engagement (United Nations, 2013). The factors that influenced the final negotiated text of the new agenda are numerous and complex, and thus, I will not touch upon these in this short contribution. What is clear, however, is that countries and agencies have recognized the degree of global interconnectedness of today's economies, industries and societies, as well as the natural environment. This complexity needed to be reflected in the new development 


\section{Li: Towards Inclusive and Sustainable Industrial Development}

agenda. There is no development on one side of the planet that does not have repercussions elsewhere. There is no carbon dioxide emission that does not contribute to global climate change, often with harsher consequences in poorer regions of the world. These intricacies complete the picture of a densely populated, resource constrained, not yet poverty-free, and increasingly warming world.

Business as usual is therefore not an option anymore. A paradigm shift - a transformative change - was vigorously debated in the international negotiations on sustainable development to ensure that the 2030 Agenda applies new approaches to accelerate progress and pave the way for the targeted ambitious, inclusive, sustainable and universal development framework.

However, we know there is no exact and universally applicable formula for development. The economic models applied to global growth policy over the past few decades have been far from flawless. State-led economies have created enormous inefficiencies and corruption, and market-driven economies have failed to take off in some instances, benefited only few in many others, and sometimes resulted in a weakening of state institutions. Inequality, both within and across countries, has increased, in many cases also in the developed world. The economic recession, from which the world is slowly and painfully recovering, reflected the limitations of laissez-faire and finance-dominated economies. Away from economics, but clearly related to it, policies and practices aimed at addressing environmental degradation and climate change have not produced significant change on the scale required to halt the disastrous effects of current trends.

Indeed, finding a universal formula to achieve sustainable development is proving elusive. Yet, we can examine history for insight into successful ways nations and communities can progress towards eradicating poverty in all its dimensions. Lessons can be learned by observing the countries that have achieved sustained levels of growth, increased employment, resilience to economic shocks, increased resource productivity and lower environmental degradation.
Whether we look at the early advancements in European countries, the USA over 200 years ago, the economic rise of Japan, or the Republic of Korea, China and the many 'tigers' and 'dragons' that achieved rapid growth more recently, we find evidence that part of the solution ultimately lies in industrial development.

History shows that only those economies that are characterized by structural transformation i.e. those exhibiting the ability to generate new activities based on upgrading to higher levels of value addition and productivity - are able to increase prosperity for a growing share of the population (Technical Support Team, 2013). The transformation typically occurs when economies move from a high dependency on agricultural activities and natural resource extraction to more diversified and productive undertakings, including industry, that foster local value addition and eventually stimulate economic development and growth. Industrialization has a pull effect on other sectors due to productive linkages, thereby enabling economic diversification and improving living standards by facilitating job creation and thus lifting large sections of a population out of poverty.

These properties of industrialization are being increasingly recognized in the international debate, after decades in which they were considered 'out of fashion' among development professionals. On the one hand, the social and economic consequences of the financial crisis revealed the need to rethink economic theory and practice (Lin, 2010) and shifted the focus to industrial policies with the rationale that markets exhibit significant inefficiencies when left to themselves. On the other hand, the evidence of industry-driven growth in emerging economies is undeniable. Finally, the imminence of environmental challenges, including climate change, draws increased attention to industry's capacity to change the current patterns of production and consumption. More specifically, the view has been aired that industrialization is a powerful tool to generate inclusive and sustained economic growth, create productive employment and decent work and lift millions of people out of poverty'. ${ }^{1}$ This view ultimately was reflected in Sustainable Development Goal (SDG) 9 


\section{Development 58(4): Upfront}

'build resilient infrastructure, promote inclusive and sustainable industrialization and foster innovation'.

Industry provides the natural seedbed for entrepreneurship, business investment and technological upgrading. It improves technical skills, generates employment and establishes the foundation for shifting the rural economic model from subsistence agriculture to productive agro-industry (Technical Support Team, 2013). Industry is also key to technology development and innovation, given that manufacturing harbours most R\&D investments, which prove to have positive externalities in terms of productivity growth and spillover effects fuelling overall economic growth. Evidence of industry's potential for putting economies on a sustained growth path is ample (UNIDO, 2014b).

The global manufacturing landscape has changed dramatically over recent years, with a significant shift of world production to developing countries. The global economic recession caused a sharp decline in production in industrialized countries and a significant slowdown in developing and emerging industrial economies. However, world manufacturing has resumed its course of sustained growth in recent years. While a thorough analysis of the recent trends on the manufacturing landscape in developed and developing countries is beyond the scope of this contribution, it is worth mentioning that the positive relationship linking manufacturing value added (MVA) and gross domestic product in developing countries reaffirms the importance of industrial transformation as the main engine of economic growth. In the Asia-Pacific region in particular, manufacturing remains a major driver of overall economic growth. However, the growth trend for developing and emerging industrial economies notably masks acute disparities between the various developing regions and countries, which must be addressed.

Despite the many challenges deriving from the recent global financial crisis, the relative resilience of manufacturing in developing and emerging industrial countries has so far shielded many people from the gravest effects of the ensuing
In sum, there is clear evidence and significant political recognition that structural transformation of economies and industries - building additional efficient and effective productive capacity, supporting economic diversification and building green industries - is key to creating growth, jobs and structures required for achieving shared prosperity.

\section{Inclusive and sustainable industrial development}

Industrialization can, of course, happen in unsustainable ways. It is widely understood that the debate should be not only about the need for an increased share of industry in an economy's output, but also about how industry actually contributes to sustainable development in all its dimensions - at the economic, social and environmental level. This is what we at UNIDO call inclusive and sustainable industrial development (ISID).

The Lima Declaration, adopted by UNIDO's Member States in December 2013, sets the foundation for ISID and highlights the role of industrialization as a driver of development. 'Inclusive' in this context means that industrial development must include all countries, all peoples, the private sector, civil society organizations, multinational development institutions and all parts of the UN system, with equal opportunities for and an equitable distribution of the benefits of industrialization to all stakeholders. The term 'sustainable' addresses the need to decouple the prosperity generated from industrial activities from excessive natural resource use and negative environmental impacts. We shall address each of these attributes below.

Inclusive industrial development therefore implies that no one is left behind and all parts of society benefit from industrial progress, which also provides the means for tackling critical social and humanitarian issues. I have already referred to the fact that industrialization has proved to be an effective poverty reduction strategy throughout modern history. The structural transformation associated with a strengthened manufacturing 


\section{Li: Towards Inclusive and Sustainable Industrial Development}

sector and the reduced dependence on agriculture has great potential to lift large segments of society including women and youth - out of poverty, providing them with a decent and stable standard of living.

For example, efficient agro-industry enhances economic stability for rural households, increases food security and promotes innovation throughout industrial value chains. Similarly, locally operating pharmaceutical and medical equipment industries are crucial to improving access to, and the quality of, health services and to increasing the number of decent jobs in this sector. Manufacturing is particularly effective in fostering jobs for women, with a higher share (33 percent) than in agriculture (28 percent) and non-manufacturing (9 percent) (UNIDO, 2013a). Furthermore, issues such as gender equality, food security, education and employment, health and public infrastructure tend to regress in the absence of a strong and growing economic base.

Of course, the benefits of industrialization need to be shared more equitably, and all segments of society need to reap its rewards and improve their living standards. The patterns of industrialization remarkably impact how the poor benefit from growth. Fiscal and industrial policies have a role to play in determining this pattern, as well as decisions made by private sector companies with regard to human resource practices, environmental performance, location and other relevant factors.

Any progress in reaching higher levels of prosperity is short-lived if the necessary economic growth is not achieved within an environmentally sustainable framework. The primary issue is not choosing between industrial growth and sustainability. It is the need to bring about a transformation in production processes, infrastructure and business models - going hand in hand with innovation and appropriate technologies - that will present the solutions to the pressing environmental challenges of our times and enable the simultaneous achievement of both economic growth and environmental sustainability.

Cleaner and more resource-efficient production methods can gradually lead to a decoupling of economic growth from environmental degradation. In this context, the drive for innovation and process optimization - reducing the waste of precious resources and thus increasing economic competitiveness - is an important means to develop the necessary solutions to realize cleaner production, efficient resource management and a reduction in waste and pollution. Energy efficiency in industry plays a particularly important role in this context, as energy inputs represent an important cost of production in all industries. Clean energy sources and energy efficiency measures are thus core determinants for future economic competitiveness and sustained industrial growth.

However, sustainability in industry cannot be driven at the company level alone, and governments need to adjust their policies - at municipal, regional and national levels - by considering suitable environmental safeguards, including waste management, water purification and pollution control measures. Green industries can be promoted to deliver important environmental goods and services, thus not only contributing to environmental sustainability but also providing additional opportunities for further structural diversification, jobs, income and prosperity.

There is thus great merit in increasing support for the transition towards clean energy, lowcarbon development and sustainable production and consumption patterns. ISID recognizes the irrefutable link between economic growth and environmental pressures and therefore encourages the promotion of 'Green Industry', as a means to not only deliver environmental goods and services, but also ensure that the economy grows in an environmentally sustainable manner. To strike this balance, industrial upgrading must innovate and optimize processes to favour cleaner production, efficient resource management and reduction in waste and pollution. In essence, ISID aims to prevent the repetition of past mistakes, such as the desire to 'grow first and clean up later' and to foster industrialization in acknowledgement of the environmental challenges.

To achieve ISID, an appropriate institutional infrastructure needs to be built, strengthened and made capable of designing, implementing and monitoring industrial policies that promote and 


\section{Development 58(4): Upfront}

encourage modern patterns of private sector development. Any successful long-term strategy and sound industrial policymaking will also need to ensure an overall framework of stable economic, legal and political conditions and create incentives for investing in the necessary education and entrepreneurial skills development for the industries of the twenty-first century. Transforming industries in an inclusive and sustainable way in all countries will also provide the basis for a long-term solution in the global struggle to generate the required levels of financing for development and will help to unleash national resources for advancing prosperity for all.

Governments will need to learn how to best identify tradable industries, introduce consistent industrial policies, fill necessary infrastructure gaps and help private firms - and SMEs in particular - to resolve information, coordination, financing and externality issues linked to technological upgrading and to gaining access to global value chains. This may also require large imports of capital equipment and technological know-how from advanced economies, thus also benefitting their advanced industrial sectors. In fact, international industrial cooperation and trade also support the diffusion of best practices and standards, both in production methods and product design, and provide opportunities for better access to modern technologies and cross-border learning. Industry plays an important role in increasing the ability of countries to continually generate new activities based on upgrading to higher levels of value addition, higher productivity, or higher returns to scale, in order to sustain stable jobs and increase prosperity for a growing share of the population.
For these reasons, the new development agenda rightly acknowledges the importance of inclusive and sustainable industrial development for achieving the overarching goal of eradicating poverty in all its dimensions and creating more equality within and among nations, while preserving the environment and advancing prosperity for all. The significance of industry for inclusive and sustainable economic growth remains undeniable. In addition to its contribution to production, exports, income, employment and poverty reduction, manufacturing significantly contributes to innovation. A robust industrial export base helps countries to recover from recessions faster than those without equivalent manufacturing sectors.

\section{Conclusion}

The challenges we face are manifold. Yet, these can, and must, be overcome. The 2030 Agenda for Sustainable Development will drive a universal effort towards addressing these challenges, as will the determination of governments, the private sector, civil society and all stakeholders involved in production, consumption and eventually sustainable development.

Only inclusive, sustainable and resilient economic and industrial growth can elevate those in extreme poverty to higher standards of living and achieve higher levels of prosperity for all. Industrialization and structural transformation, when they are inclusive and sustainable in the terms described in this contribution, can help create, sustain and support peaceful and more prosperous societies.

\section{Note}

1 Excerpt from the Statement delivered by H.E. Mr. Thomson (Permanent Representative of Fiji to the UN and chair of the G-77) on behalf of the Group of 77 and China at the fourth session of the General Assembly Open Working Group on Sustainable Development Goals (SDGs), New York, 17 June 2013.

\section{References}

Lin, Justin (2010) 'Industrial Policy Comes Out of the Cold', Project Syndicate. Available at http://www.projectsyndicate.org/commentary/industrial-policy-comes-out-of-the-cold, accessed 24 October 2014. 


\section{Li: Towards Inclusive and Sustainable Industrial Development}

Technical Support Team (2013) 'TST Issues Brief: Sustained and Inclusive Economic Growth, Infrastructure Development, and Industrialization', http://sustainabledevelopment.un.org/content/documents/2078Draft\% 20Issue\%20Brief_Sustained\%20and\%20Inclusive\%20Economic\%20Growth_Final_160ct.pdf.

UNIDO (2013a) 'Industrial Development Report 2013: Sustaining Employment Growth: The Role of Manufacturing and Structural Chage', Vienna: UNIDO.

UNIDO (2014b) 'Inclusive and Sustainable Industrial Development (ISID): The Why, What and How'. Unpublished background paper.

United Nations (2013) 'A New Global Partnership: Eradicate Poverty and Transform Economies through Sustainable Development. The Report of the High-Level Panel of Eminent Persons on the Post-2015 Development Agenda'. New York: United Nations.

\section{Further readings}

Acemoglu, Daron and David Autour (2010) 'Skills, Tasks and Technologies: Implications for Employment and Earnings'. NBER Working Paper 16082. Cambridge, MA: National Bureau of Economic Research.

Division for Sustainable Development, UN-DESA (2013) 'Special Report of SD in Action Newsletter: Voluntary Commitments and Partnerships for Sustainable Development'. Issue 1.

Marx, Axel and Jadir Soares (2013) 'Networks for Prosperity: Partnering for inclusive and sustainable industrial development'. Vienna: UNIDO.

OECD (Organization for Economic Cooperation and Development) (2014) 'Perspectives on Global Development', Paris: OECD Publishing.

Robinson, James A (2009) 'Industrial Policy and Development: A Political Economy Perspective'. Paper prepared for the 2009 World Bank ABCDE Conference, Seoul, 22-24 June 2009.

Rodrik, Dani (2010) 'The Return of Industrial Policy’, Project Syndicate. Available at http://www.project-syndicate. org/commentary/the-manufacturing-imperative, accessed October 2014.

Tregenna, Fiona (2013) 'Manufacturing Productivity, Deindustrialization and Reindustrialization', in Adam Szirmai, Wim Naudé and Ludovico Alcorta (eds.), Pathways to Industrialization in the 21st Century. New Challenges and Emerging Paradigms, Oxford: Oxford University Press.

Ullveit-Moe, Karen Helene (2008) 'Live and Let Die-Industrial Policy in a Globalised World'. Expert Report 22 to Sweden's Globalisation Council. Västerås, Sweden: Globalisation Council.

UNIDO (2013b) International Yearbook of Industrial Statistics 2013. Vienna: UNIDO.

UNIDO (2013c) 'Networks for Prosperity- Partnering for Inclusive and Sustainable Industrial Development: Connectedness Index 2013'. Vienna: UNIDO.

UNIDO (2014a) 'Report of the Director General of the United Nations Industrial Development Organization'. Vienna: UNIDO.

United Nations, General Assembly, Open Working Group proposal for Sustainable Development Goals, A/68/970 (12 August 2014), Available at http://undocs.org/A/68/970. 